\title{
Informational Privacy in the Recovery Room-Patients' Perspective
}

\section{Koivula-Tynnilä, Hannele}

2018-08

Koivula-Tynnilä , H , Axelin , A \& Leino-Kilpi , H 2018, ' Informational Privacy in the

Recovery Room-Patients' Perspective ' , Journal of PeriAnesthesia Nursing , vol. 33 , no. 4 , pp. 479-489 . https://doi.org/10.1016/j.jopan.2016.12.004

http://hdl.handle.net/10138/304170

https://doi.org/10.1016/j.jopan.2016.12.004

publishedVersion

Downloaded from Helda, University of Helsinki institutional repository.

This is an electronic reprint of the original article.

This reprint may differ from the original in pagination and typographic detail.

Please cite the original version. 


\title{
Informational Privacy in the Recovery Room-Patients' Perspective
}

\author{
Hannele Koivula-Tynnilä, MNSc, RN, Anna Axelin, PbD, RN, \\ Helena Leino-Kilpi, PbD, RN, FEANS
}

\begin{abstract}
Purpose: To describe patients' perceptions of informational privacy and factors promoting it in the recovery room.

Design: A descriptive semistructured qualitative interview study.

Methods: The study was conducted in 2013, and the data were analyzed with inductive content analysis. Adult surgical recovery room patients ( $n$ $=17)$ were recruited with purposive sampling at the Department of Ear, Nose and Throat diseases in a university hospital in Finland. Findings: Informational privacy was described as control of patients' bealth information maintained by the bealth care professionals and the patients. Informational privacy was especially important in relation to other patients. Health care professionals and patients' attitude, behavior, and knowledge of informational privacy, barriers of hearing and seeing, societal rules, and the electronic patient data system promoted informational privacy.

Conclusions: Informational privacy in relation to other patients could be improved in the recovery room, for example, by developing patient health information transmission and architectural solutions.
\end{abstract}

Keywords: informational privacy, patient bealth information, recovery room, acute care.

(C) 2016 by American Society of PeriAnesthesia Nurses

INFORMATIONAL PRIVACY IS an important principle in health care. It supports patients' dignity, self-determination, ${ }^{1-3}$ and patient safety. ${ }^{4}$ However, the protection of patients' health information is found to be the weakest part of good patient care in surgical wards. ${ }^{5}$ Informational privacy

\footnotetext{
Hannele Koivula-Tynnilä, MNSc, RN, Department of Nursing Science, University of Turku, and Ambulatory Surgery Unit for Ear, Nose and Throat Diseases, Helsinki University Hospital, Finland; Anna Axelin, PhD, RN, Department of Nursing Science, University of Turku, Finland; and Helena Leino-Kilpi, PbD, RN, FEANS, Department Nursing Science, University of Turku, and Turku University Hospital, Turku, Finland.

Conflict of interest: None to report.

Address correspondence to Hannele Koivula-Tynnilä, Haukkakallio 2 D 8, 02620 Espoo, Finland; e-mail address: hannele.tynnila@hotmail.com.

(C) 2016 by American Society of PeriAnesthesia Nurses $1089-9472 / \$ 36.00$

http://dx.doi.org/10.1016/j.jopan.2016.12.004
}

is not always respected, ${ }^{6,7}$ and there is limited confidentiality of patient health information in the hospital wards. ${ }^{7-11}$

Informational privacy concerns information related to patient's health, how it should be protected, and who has the right to access it. ${ }^{12,13}$ Informational privacy is defined as the patient's right to decide how, when, and how much information they are willing to share with another person ${ }^{14}$ or in the health care organization. ${ }^{1}$ The main content of informational privacy is considered to be the confidentiality of the patient's health information. ${ }^{12,15}$

Informational privacy has an ethical and legal dimension in health care. In this study, the ethical dimension is investigated from the patients' perspective in the context of the recovery room. Informational privacy is protected by the ethical 
codes of nurses and physicians. ${ }^{15-17}$ National legal acts regarding the handling of patient health information are connected by International human rights. ${ }^{18,19}$

Patients are increasingly aware of their rights for privacy, and they expect these rights to be ensured in health care organizations. ${ }^{20}$ Patients may share with health care professionals issues that they do not always share even with their significant others. The increasing capability to store and distribute patients' health information with the help of information technology highlights the importance of the protection of informational privacy. ${ }^{12}$ Patient safety can also be at risk if patients feel unsafe sharing their private information with health care professionals. ${ }^{4,8}$ This is especially true in the recovery room, where the patient is in a vulnerable position under sedative medication, possibly with many patients in the same room at the same time.

The context of this study is a hospital, more precisely, the recovery room. In the hospital setting, patients' perspective of informational privacy has been studied mostly in medical and surgical wards. Patients in long-term care had previously expressed higher expectations of informational privacy than patients in acute care. ${ }^{6}$ However, recent studies in acute care settings such as emergency departments ${ }^{10,11,21,22}$ indicate that patients in acute care may have become more critical toward the lack of informational privacy than in earlier studies.

To our knowledge, there is only one study pertaining to informational privacy in the recovery room. As early as 1968 , Mincley $^{23}$ observed that the patients controlled their privacy in the recovery room by ignoring fellow patients' presence, hiding behind the cover, or turning their faces toward the wall. Both patients and nurses lowered their voices when communicating because there were no visual or auditory barriers in use. ${ }^{23}$

Recovery rooms have challenges in promoting patients' privacy. To ensure patient safety, nurses need to exchange patient information ${ }^{24}$ and observe the patients continuously. ${ }^{25}$ There are also multiple staff members participating in patient care. ${ }^{26}$ In addition, the increased number of ambulatory surgery procedures puts pressure to share more information with the patient immediately after surgery in the recovery room. At the same time, many operations are performed under regional anesthesia and with short-acting sedative medication so that patients can be discharged quickly; therefore, they are more aware of the events around them. All this puts new challenges to adequate protection of patients' informational privacy. The aim of this interview study was to describe, with an inductive approach, patients' perceptions of informational privacy and factors promoting it in the recovery room.

\section{Methods}

The study was conducted as a descriptive qualitative interview study. This design is used when there is scarce information about the phenomenon under investigation. ${ }^{27}$ This design allows the researchers to get a comprehensive understanding of the patients' perceptions of informational privacy in the recovery room. ${ }^{28}$

\section{Settings and Sample}

The data collection took place in July to September 2013 in the Department of Ear, Nose and Throat (ENT) diseases in one of five university hospitals in Finland. This department was chosen because of the high number of operations and the expectations of having several patients in the recovery room at the same time.

The ENT Department recovery room was located next to the operating rooms. Approximately $20 \mathrm{pa}$ tients per day, representing both genders and aged greater than 6 months, were taken care of in the same recovery room. ${ }^{29}$ Some of the patients had problems with hearing and in communication because of hearing loss or laryngotracheal operations.

The patients were observed and cared for postoperatively by the recovery room nurses. Information about the patients was exchanged verbally among staff at the patients' bedside after the operation, and when they were transferred to the postoperative ward. Patient folders were kept on a table next to the bed.

There were screens between the patients, which could be drawn out if needed (Figure 1). Each 
patient had one nurse with main responsibility for their care in the recovery room. Family members were not allowed to visit adult patients in the recovery room.

In this department, the recovery room stay lasted a median of 1 to 2 hours, ranging from 15 minutes up to 24 hours. Two to six nurses worked at the same time in the recovery room. Anesthesiologists, surgeons, nurses from other wards, and assistant nonmedical staff increased the number of personnel from time to time.

The patients were recruited using purposive sampling. ${ }^{30}$ Recruitment was performed at two surgical wards of the ENT Department. In these wards, nurses ascertained the patients' willingness to participate in the study on the day of the operation.

The inclusion criteria were as follows: patients aged greater than 18 years, Finnish speaking, and able to hear and speak normally. Among the patients willing to participate, the ones whose stay in the recovery lasted longer than 30 minutes and who had other patients in the recovery room at the same time with them were recruited. Data were collected and analyzed simultaneously. Patients were recruited until data saturation was reached.

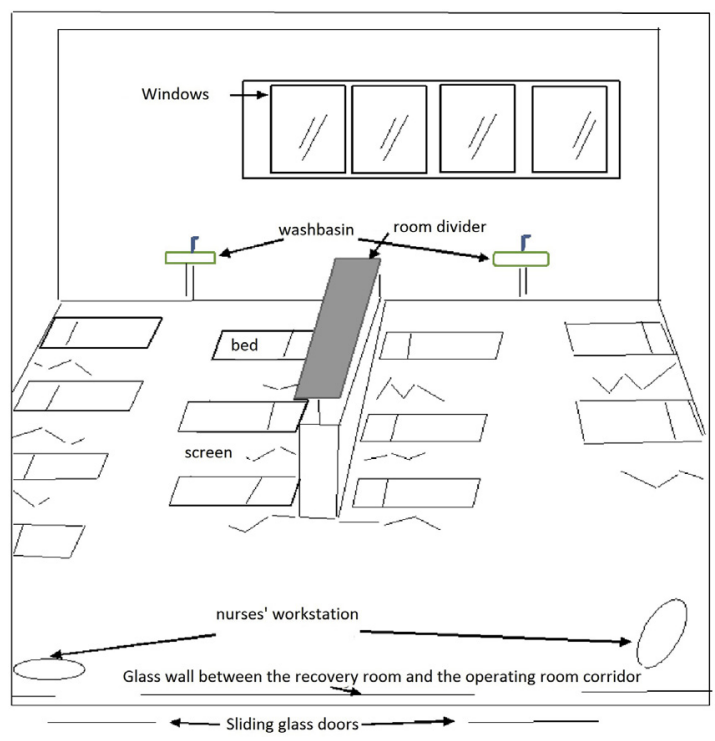

Figure 1. Layout of the recovery room. This figure is available in color online at www.jopan.org.

\section{Interviews}

The recorded interviews conducted by the researcher (H.K.-T.) took place 1 or 2 hours after the patient had been discharged from the recovery room, in a single room in the postoperative ward. The patients were not transferred to the postoperative ward before they were fully conscious, their respiration and cardiovascular function had returned to preoperative level, and their bleeding, pain, and nausea were appropriately controlled. ${ }^{31}$ In addition, the researcher made sure the patient was ready for interview by confirming the patient did not suffer any pain or nausea and that the patient generally felt in good enough condition for the interview. The interview was carried out only if the patient felt strong enough for the interview. None of the interviews were stopped because of the patients' unstable condition or for any other reason. The interviews lasted approximately $24 \mathrm{mi}-$ nutes (ranging from 14 to 43 minutes). A semistructured interview guide with the following main themes was used: (1) how did the patient perceive informational privacy, (2) how did the patient perceive the realization of informational privacy in the recovery room, and (3) what were the factors promoting informational privacy in the recovery room? To describe the participants, the following background information was collected: participant's age, gender, education, the type of anesthesia (general or local) and operation, the number of previous hospitalizations, the length of stay in the recovery room, and patient satisfaction (scale 0 the worst to 10 the best grade) with (1) nursing care and (2) pain management and opinion of their well-being in the recovery room.

\section{Data Analysis}

The verbatim data were analyzed with inductive content analysis. ${ }^{27}$ The data were searched for meaningful descriptions of informational privacy. Key sentences and phrases were coded using in vivo codes. ${ }^{30}$

The in vivo codes were categorized and named under the indigenous concepts. The indigenous concepts were then summarized into patterns and major themes describing patients' experiences of informational privacy. The major themes were named so that they described the content 
of the indigenous concepts. In vivo codes, indigenous concepts, patterns, and major themes were organized into a matrix (Table 1). The use of indigenous concepts and careful reviewing of the formed major themes ensured that the findings were described from the perspective of the patients. $^{30}$

\section{Etbical Considerations}

The study protocol received ethical approval from the Ethical Committee of the University of Turku and the permission to conduct the study by the authorities of the university hospital.

The patients received written and verbal information about the study on the day of the operation at the hospital. They had 3 to 7 hours to consider participation in the study. The patients informed the nurse on the ward about their willingness to participate, after which the researcher met the patient. Written informed consent was obtained from each participant. The research findings are reported anonymously.

\section{Findings}

The participants' $(n=17)$ mean age was 49 years (range 20 to 83). Both genders were represented (eight females, nine males). Their educational background was mainly 12 years of basic education plus 3.5 years of upper secondary level education $(n=11)$, those with 12 years of basic education plus academic education

Table 1. Example of the Formation of In Vivo Codes Into a Major Theme

\begin{tabular}{|c|c|c|c|}
\hline In Vivo Codes & Indigenous Concepts & Pattern & Major Theme \\
\hline $\begin{array}{l}\text { Does the patient information } \\
\text { remain confidential between } \\
\text { the nurse and the patient? }\end{array}$ & $\begin{array}{l}\text { Confidentiality in } \\
\text { communication }\end{array}$ & $\begin{array}{l}\text { Informational privacy } \\
\text { controlled by professionals }\end{array}$ & $\begin{array}{l}\text { Twofold control of } \\
\text { patient information }\end{array}$ \\
\hline \multicolumn{4}{|l|}{$\begin{array}{l}\text { Privacy of personal health } \\
\text { information, so that the } \\
\text { nurses do not disclose my } \\
\text { background or information } \\
\text { about the operation to } \\
\text { outsiders in the recovery } \\
\text { room }\end{array}$} \\
\hline $\begin{array}{l}\text { Private information is available } \\
\text { only to the professionals } \\
\text { taking care of the patient }\end{array}$ & $\begin{array}{l}\text { Confidential access } \\
\text { to patient } \\
\text { information }\end{array}$ & & \\
\hline \multicolumn{4}{|l|}{$\begin{array}{l}\text { Patient information belongs } \\
\text { only to the team taking care } \\
\text { of the patient }\end{array}$} \\
\hline $\begin{array}{l}\text { I want to control what } \\
\text { information I share and with } \\
\text { whom }\end{array}$ & $\begin{array}{l}\text { Limited information } \\
\text { sharing }\end{array}$ & $\begin{array}{l}\text { Informational privacy } \\
\text { controlled by patients }\end{array}$ & \\
\hline \multicolumn{4}{|l|}{$\begin{array}{l}\text { If the information is } \\
\text { unnecessary for the doctor, } \\
\text { for example, former } \\
\text { psychological problems, I do } \\
\text { not think he should get to } \\
\text { know it }\end{array}$} \\
\hline $\begin{array}{l}\text { The patient should have a right } \\
\text { to hear his own health } \\
\text { information in the recovery } \\
\text { room }\end{array}$ & $\begin{array}{l}\text { Access to own } \\
\text { patient } \\
\text { information }\end{array}$ & & \\
\hline $\begin{array}{l}\text { I should have a right to see and } \\
\text { get the health information } \\
\text { about me }\end{array}$ & & & \\
\hline
\end{tabular}


$(n=5)$ and 6 years of schooling $(n=1)$ being in the minority. ${ }^{32}$

The participants were operated under general anesthesia $(n=15)$ or local anesthesia $(n=2)$. The operations included tonsillectomy $(\mathrm{n}=6)$, parotidectomy $(n=4)$, nose $(n=4)$, and throat or thyroid gland operation $(\mathrm{n}=3)$. Most of the patients $(n=16)$ had been previously hospitalized on average three times (range 0 to 10). Their recovery room stay lasted a median of 50 minutes (range 30 minutes to 5 hours 30 minutes). There were two to nine patients in the recovery room at the same time with the participants. The participants rated their satisfaction with a mean of 8.9 on nursing care, 9.7 on pain management, and 8.7 on general well-being of the patient in the recovery room.

\section{Informational Privacy From the Patients' Perspective}

The patients described informational privacy as twofold control of their health information: (1) control by professionals and (2) control by the patient (Figure 2). Health care professionals were expected to control the confidentiality in communication and in access to patient health information. The patients controlled their health information by limiting the sharing of verbal or written information with the health care professionals and having access to their own information. This access meant availability of the patients' written and verbal health information.

The first thought in a hospital is that not everybody should hear about my matters. 1:24 (number of the code in ATLAS.ti 6.1 program)

The informational privacy concerns how I'm able to control the information about me that is spread around the hospital. 16:95

The expectations on confidential communication in the recovery room varied between the patients. Some of the patients representing the other end of the continuum considered informational privacy as an unconditional principle, which should not be violated under any circumstances. They found confidential communication especially important in relation to hospital roommates, their acquaintances, and with patients representing the opposite sex. However, the patients were ready to balance informational privacy in relation to patient safety. The acuity of care entitled health care professionals to compromise confidential

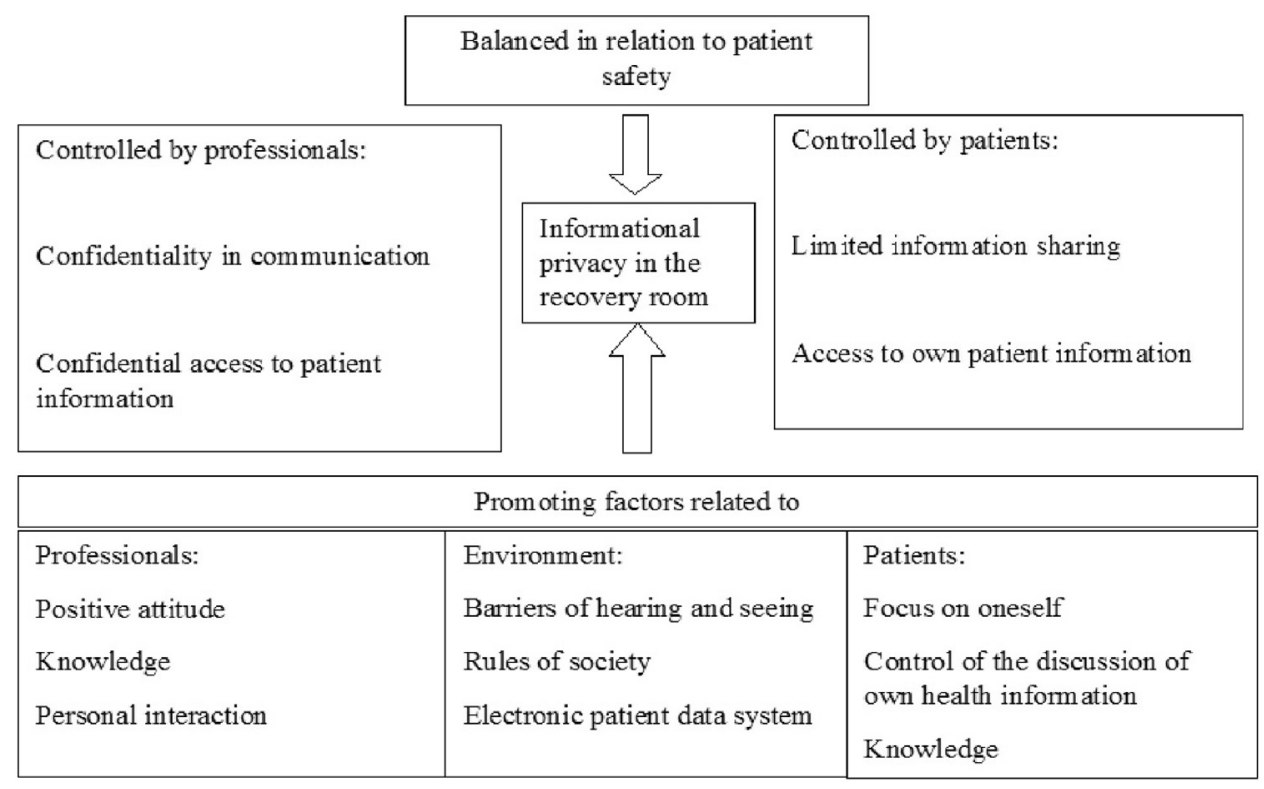

Figure 2. Patient perspective of informational privacy and the promoting factors in the recovery room. Printed with permission from Hannele Koivula-Tynnilä. 
communication. The patients perceived that health care professionals had to exchange information about the patient to ensure safe patient care, for example, during a life-threatening situation, although other patients could hear the discussion.

Obviously, confidentiality of patient information doesn't matter if I'm dying. The situation makes a difference. If you are really fighting for your life, then it does not matter. 7:126

Confidential communication was not a priority for all the patients in the recovery room. This neutral attitude was ascribed to the fact that the patients did not consider their ENT diseases to be very sensitive or serious. If they had had more sensitive or serious issues, such as an incurable illness, they would have liked to receive the information privately, not in the recovery room.

If you'd have some sensitive illness, maybe you'd take it differently. Maybe an incurable illness would influence it, if you are really seriously ill. Then you'd need more privacy. 11:60

Access to written patient information was expected to be limited only to the health care professionals taking care of the patients. The patients held health care professionals responsible for obtaining the necessary information concerning patients' care to secure patient safety. The patients allowed access to their health information also to the health care professionals who were not directly involved in their care if it benefited their care. They described it as a chance to get a second opinion. However, the patients did not consider it acceptable for any of the health care professionals to search for irrelevant, possibly stigmatizing information, such as psychological or gynecologic problems, in regard to their current care.

If there were for example psychological problems in the patient's history, it would be unpleasant if these were dragged out and would affect the care you get later. They should not prejudice or stigmatize you. 16:1

Selective sharing of patients' own health information helped them to create a positive image of themselves in relation to the other patients. This positive image on its part supported the patients' integrity and dignity in the recovery room. On the other hand, sharing of own feelings and experiences with other patients was seen as part of the hospital care.

The other patients are not allowed to hear my patient information. I create an image of myself and let the others hear what I want them to hear. 5:82

In my case, there is no such information (secret), you hear it in the patient room anyway. I think it belongs to the hospital that you discuss with the other patients about your disease history. 11:58

The patients described the access to their own health information as a prerequisite for the control of patients' informational privacy. Although many of the patients were especially interested in what the doctor had written in their medical records, they did not want to explore this information in the recovery room. They did not feel capable of reading or receiving detailed information immediately after the operation.

Patients' Perception of the Realization of Informational Privacy in the Recovery Room

REALIZATION OF INFORMATIONAL PRIVACY CONTROLLED BY HEALTH CARE PROFESSIONALS. On the basis of the patients' experiences, the realization of confidential communication varied. The discussions with the patient were often done anonymously, and the content mostly concerned postoperative pain and the patient's overall well-being after the operation. Some of the patients had not heard any sensitive patient information in the recovery room, whereas others had been able to hear about the other patients' operations and medical history, and at times, to identify the patient. Hearing of other patients' health information was perceived as embarrassing. Opinions were divided concerning disclosure of patient's name or identification number. Some of the patients thought that addressing them by name was natural and that identifying the right patient was more important than protecting 
identity. Others worried about the disclosure and possible misuse of their name and identification number.

Confidential access to patient health information was perceived to be properly realized in the recovery room. The patients perceived that only the nurses and the physicians taking care of them had read their health information in the recovery room.

\section{REALIZATION OF INFORMATIONAL PRIVACY} CONTROLLED BY THE PATIENT. The patients limited the sharing of their health information verbally in the recovery room. They refrained from asking questions about their current condition to limit disclosure of their health information to the other patients.

Access to one's own health information in the recovery room was ensured by receiving verbal information from the health care professionals. The patients were interested in whether the operation had been successful and if everything had gone well. Several patients were also interested in physiological measures such as blood pressure, heart rate, or their blood sugar level. The patients perceived they had received enough verbal information about their health in the recovery room.

\section{Factors Promoting Informational Privacy in the Recovery Room}

The factors promoting informational privacy were divided into three subcategories: factors related to (1) health care professionals, (2) patients, and (3) environment (Figure 2).

Promoting factors related to health care professionals consisted of positive attitude and knowledge of informational privacy and personal interaction with the patient. Health care professionals' positive attitude and knowledge of informational privacy was perceived to be the foundation of its realization. The patients trusted that health care professionals obey the laws, organizational regulations, and their ethical guidelines concerning informational privacy. They assumed that health care professionals gained knowledge of informational privacy from their training and updated it regularly.
It is not about some big structural changes or maneuvers. It is merely the attitude of the healthcare professionals. It has a major role in this matter. 7:131

Personal interaction between nurses and patients promoted informational privacy in the recovery room. The nurses working in the recovery room came to the patient's bed and used an appropriate voice to discuss with them.

I have noticed that the nurses here are very special, or they have learned to use their voices so that you feel they talk to you very personally. 1:90

Promoting factors related to the patients consisted of patients focusing on themselves, controlling the discussion of their health information, and knowledge about informational privacy protection. The patients focused on themselves and did not pay attention to the other patients in the recovery room. Some of the patients had difficulties hearing or seeing as they did not have their hearing aid or eyeglasses with them. This shut out the presence of the other patients even more. They also described that good manners prevented them from listening to the other patients' information. The same kind of solidarity behavior was expected from the other patients.

After the operation, everybody is so focused on oneself, you aren't interested in other peoples' issues. 4:3

A few patients thought they could control the health care professionals' discussions of their health information by forbidding them to do so. However, this would have required them to be awake and to have enough courage to express their opinion to nurses. Some of the patients perceived they could have contributed more to the implementation of informational privacy in the recovery room if they had known how it was protected in the hospital.

Promoting factors related to the environment consisted of barriers of hearing and seeing, rules of society, and the electronic patient data system. 
Barriers of hearing and seeing indicated sufficient distance between patient beds, screens, soundproof spaces, and limited entry to the recovery room. Sufficient distance and the screens between the beds in the recovery room prevented patients from seeing each other and prevented them from linking the health information to the right patient.

They seemed to use screens in the recovery room and in here (the ward room). You get a feeling of a personal space. 1:56

The patients suggested that nurses should have a soundproof office where they could discuss patient issues, for example, consult the doctor. They also suggested soundproof areas where health care professionals and patients could have personal discussions.

Space design is something you could promote. As I said, the curtains are quite cheap investment, and if the nurses had some kind of a soundproof box, where they could do the telephone calls like "Mrs. Smith is ready to be picked up from the recovery room." Then nobody knows who is it, the names will not be disclosed to the others. 6:82

Limited entry to the recovery room made the patients assume there were no outsiders. They also assumed that the nurses controlled the access to the patients' medical records from any irrelevant people in the recovery room.

I don't believe that anyone not belonging to the staff could even have access to the recovery room, nobody could get in there unnoticed. 1:49

Rules of society referred to the legal, ethical, and organizational regulation on informational privacy and the sanctions of breaking the rules. The patients perceived that these rules promoted patients' informational privacy. In addition, the use of a checklist was suggested to ensure that informational privacy was maintained in the recovery room.
The patients perceived that an electronic patient data system, which was not in use at the time of the study, would promote informational privacy. It was assumed to hinder outsiders from handling patients' health information as the person who accessed them could be tracked afterward.

I have understood that it can be seen that you have read someone's patient health information even though you are not taking care of that patient at the time. 7:110

\section{Discussion}

This study suggests that patients' perspective of informational privacy in the recovery room relates to the control of their health information. This control is maintained by both health care professionals and patients. The concept of control emerged because the patients described informational privacy not only as protection of their health information, but also as their active role in having access to it and making decisions about the disclosure of it.

The concept of informational privacy evolved with the results of this study. This study extends patients' former perceptions of the concept, confidentiality, ${ }^{22,33-35}$ and access to health information, ${ }^{33,36,37}$ to also encompass patients' active role in making decisions about the disclosure of their health information.

Patient safety was seen as a factor that in lifethreatening situations overrides informational privacy. This point of view could have emerged because of the patients' acute situation after a surgical procedure. Privacy as a situational concept ${ }^{14,38}$ can also be seen in this. The patients' desired level of privacy differed depending on how they were coping postoperatively. Health care professionals' high ethics and knowledge of informational privacy are especially highlighted in situations where patients lower their expectations for privacy because of their own safety, as was noted in this and an earlier study. ${ }^{4}$

Health care professionals' confidentiality in their clinical practice, especially in verbal communication, was seen as a major contributor to the realization of informational privacy in the recovery room. 
This supports the earlier research conducted in emergency departments and medical and surgical wards. ${ }^{4,21,22,33,39,40}$ In this study, the patients were mostly satisfied with confidential communication. Health care professionals' careless disclosure of patient health information has been reported earlier in emergency and oncology wards and primary care. ${ }^{8,11,37}$ The satisfaction with confidential communication seen in this study may be explained by patients' good satisfaction level with their care in the recovery room. In addition, sensitive issues that should be discussed privately ${ }^{4,41}$ were not discussed in the recovery room.

Confidential access to patient health information was perceived to be well realized in the recovery room. Medical records on a table by the patient's bedside did not expose confidential health information to other patients in the recovery room, unlike in an earlier study. ${ }^{37}$ This is probably because in the recovery room, patients normally stay in bed as opposed to primary care setting where they can move more freely. Patients trust the health care professionals, also those not directly involved in their care, in the recovery room, as also seen in earlier studies. $3,36,39,42-46$ This trust the patients express in health care professionals indicates that professionals have managed to preserve the ethical demands implemented into the profession. However, this trust did not concern stigmatizing information, as indicated also in earlier studies. ${ }^{33,42,45}$ This suggests that health care professionals' confidential access to patient information also remains important to patients. ${ }^{4}$

Patients' awareness and active role in controlling their health information seem to be increasing. Patients limited the sharing of their health information, which has also been presented in earlier studies. $3,4,11,22,33,47$ Access to their own information was seen as a prerequisite to being able to control its future disclosure in health care in this study. Limiting of the sharing of health information may cause risks to patient care. Patients are not always able to evaluate which information is relevant for their treatment, which is why health care professionals have to maintain their trustworthiness to preserve patients' confidence in them. Their health problems may also remain unnoticed as a result of limiting the sharing of their health information, as shown also in an earlier study of former hospital patients. ${ }^{4}$

Environmental factors, such as sufficient distance and screens between the patients, played an important role in promoting patients' informational privacy in this study. Previously, patients have found curtains to be an insufficient protection for informational privacy in conversations. ${ }^{4,10,11}$ Because environmental limitations make providing private space in the recovery room difficult, using all the available means to secure informational privacy is important. Information technology, for example, electronic patient data systems, offers health care professionals new opportunities to confidential communication about patient health information. These possibilities of architecture should also be exploited. Some intensive care units have glass walls, which are bright on top and dimmed at the bottom. These kinds of walls could provide the patients more privacy in the recovery room as shown in the earlier studies in the emergency units. $^{10,11}$

\section{Limitations}

The limitations of the study have to do with credibility, dependability, and transferability. ${ }^{48}$ Credibility of the study relates to the focus of the phenomenon of interest and how well the data and analysis processes manage to obtain relevant information. ${ }^{48}$ Lack of a universal definition of the concept of informational privacy made the development of a structured interview guide challenging; therefore, a semistructured interview guide with an inductive approach was chosen. In vivo coding and the indigenous concepts used in data analyses aimed to remain loyal to the patients' voice and resulted in an extended description of the concept compared with earlier studies, which had mainly focused on confidentiality. General anesthesia and other sedative medication could have had an impact on the patients' recall and may have affected the credibility of the findings.

Dependability ${ }^{48}$ of the interviews was assured with the semistructured guide. This helped to maintain the structure and focus of the interviews in informational privacy but allowed additional 
questions at the same time. The researcher is familiar with ENT diseases and recovery room nursing. This helped her to interpret the patients' descriptions of the events in the recovery room and separate those from the events in the postoperative wards.

The transferability ${ }^{48}$ of the study has certain limitations. The lack of young, especially female patients, in the study may have affected the results because they have the highest expectations for privacy in the hospital. ${ }^{6,33,45}$ The youngest participant in the study was 20 years old, whereas the others were aged between 36 and 83 years. ENT diseases were also found to be quite a nonsensitive illness entity. More sensitive health problems may result in more critical views on informational privacy.

\section{Conclusions}

This research has shown that means are needed to protect patient health information in the recovery room, especially from the other patients. There is a gap between informational privacy regulation and its realization. Realization of informational privacy affects patient safety if patients do not have the courage to share their health information with the health care professionals. Hospital architecture and the lack of privacy because of the demand of continuous observation of patients pose challenges to informational privacy in the recovery room. The capabilities of electronic patient records and technological solutions (eg, mobile applications) in patient information transmission between health care professionals and architectural solutions should thus be advanced.

\section{References}

1. Leino-Kilpi H, Välimäki M, Arndt M, et al. Patients'Autonomy, Privacy and Informed Consent, Biomedical and Health Research. Amsterdam: IOS Press; 2000.

2. Beauchamp TL, Childress JF. Principles of Biomedical Ethics, 6th ed. New York: Oxford University Press; 2009.

3. Eklöf N, Abdulkarim H, Hupli M, Leino-Kilpi H. Somali asylum seekers' perceptions of privacy in healthcare. Nurs Ethics. 2016;25:535-546.

4. Malcolm HA. Does privacy matter? Former patients discuss their perception of privacy in shared hospital rooms. Nurs Ethics. 2005;12:156-166.

5. Eloranta S, Katajisto J, Leino-Kilpi H. Potilas kirurgisen hoidon laadun arvioitsijana. Hoitotiede. 2008;20:115-125.

6. Bäck E, Wikblad K. Privacy in hospital. J Adv Nurs. 1998; 27:940-945.

7. Merakou K, Dalla-Vorgia P, Garanis-Papadatos T, KoureaKremastinou J. Satisfying patients' rights: A hospital patient survey. Nurs Ethics. 2001;8:499-509.

8. Søndergård Larsen L, Hedegaard Larsen B, Birkelund R. A companionship between strangers-The hospital environment as a challenge in patient-patient interaction in oncology wards. $J$ Adv Nurs. 2013;70:395-404.

9. Woogara JR. Patients' privacy of the person and human rights. Nurs Ethics. 2005;12:273-287.

10. Nayeri ND, Aghajani M. Patients' privacy and satisfaction in the emergency department: A descriptive analytical study. Nurs Ethics. 2010;17:167-177.

11. Karro J, Dent AW, Farish S. Patient perceptions of privacy infringements in an emergency department. Emerg Med Australas. 2005; 17:117-123.

12. Leino-Kilpi H, Välimäki M, Dassen T, et al. Privacy-A review of the literature. Int J Nurs Stud. 2001;38:663-671.

13. European Parliament and Council. Protection of personal data. Directive 95/46. 2014. Available at: http://eur-lex. europa.eu/legal-content/EN/LSU/?uri=CELEX:31995L0046\&qid= 1458071691646. Accessed October 28, 2015
14. Westin AF. Privacy and Freedom. New York: Athens; 1970 .

15. Goodwin L, Courtney K, Kirby JD, Iannacchione MA, Manley T. A pilot study: Patients' perceptions about the privacy of their medical records. Online J Nurs Inf. 2002;6. Available at: http://ojni.org/1002/courtney.htm. Accessed March 29, 2016.

16. International Council of Nurses. The ICN Code of Etbics for Nurses. 2012. Available at: http://www.icn.ch/images/stories/ documents/about/icncode_english.pdf. Accessed May 21, 2014.

17. World Medical Association. WMA International Code of Medical Ethics. 2012. Available at: http://www.wma.net/en/ 30publications/10policies/c8/. Accessed March 16, 2016.

18. European Court of Human Rights, Council of Europe. The European Convention on Human Rights. 1950. Available at: http://www.echr.coe.int/Documents/Convention_ENG.pdf. Accessed April 27, 2014.

19. United Nations. The Universal Declaration on $\mathbf{H u}$ man Rights. 1948. Available at: http://www.un.org/en/ universal-declaration-human-rights/index.html. Accessed March $16,2016$.

20. Woogara J. Patients' rights to privacy and dignity in the NHS. Nurs Stand. 2004;19:33-37.

21. Kerr K, McKay K, Klim S, Kelly A-M, McCann T. Attitudes of emergency department patients about handover at the bedside. J Clin Nurs. 2013;23:1685-1693.

22. Lin Y-K, Lin C-J. Factors predicting patients' perception of privacy and satisfaction for emergency care. Emerg Med J 2010;28:604-608.

23. Mincley B. Space and place in patient care. Am J Nurs. $1968 ; 68: 510-516$.

24. Choromanski D, Frederick J, Mckelvey GM, Wang H. Intraoperative patient information handover between anesthesia providers. J Biomed Res. 2014;28:383-387.

25. Cutugno C. Evolution of postanesthesia care units: A legacy of politics, funding, and patient safety concerns. Policy Polit Nurs Pract. 2013;14:142-150. 
26. Smith AF, Mishra K. Interaction between anaesthetists, their patients, and the anesthesia team. Br J Anaesth. 2010; 105:60-68.

27. Huberman AM, Miles MB. Data management and analysis methods. In: Denzin NK, Lincoln YS, eds. Handbook of Qualitative Research. Thousand Oaks, CA: SAGE Publications; 1994.

28. Sandelowski M. Whatever happened to qualitative description? Res Nurs Health. 2000;23:334-340.

29. Helander J. Report of operation room activities in the department of Ear-, Nose- and Throat diseases-Opera-statistics. Presentation, January 2013.

30. Patton MQ. Qualitative Research \& Evaluation Methods, 3rd ed. Thousands Oaks: Sage Publications; 2002.

31. Vimlati L, Gilsanz F, Goldik Z. Quality and safety guidelines of postanaesthesia care. Working Party on Post Anaesthesia Care. Eur J Anaesthesiol. 2009;26:715-721.

32. Ministry of Education and Culture. Education System in Finland. 2016. Available at: http://www.minedu.fi/OPM/ Koulutus/koulutusjaerjestelmae/?lang=en. Accessed December 4, 2016.

33. Jantunen K, Puumalainen A, Suominen T, Leino-Kilpi H. Onko sairaalassa yksityisyyttä. Hoitotieteen laitoksen julkaisuja A:5. Turku: Turun yliopisto; 1994.

34. Cahill J. Patient's perceptions of bedside handovers. $J$ Clin Nurs. 1998;7:351-359.

35. Lin Y-P, Tsai Y-F, Chen H-F. Dignity in care in the hospital setting from patients' perspectives in Taiwan: A descriptive qualitative study. J Clin Nurs. 2011;20:794-801.

36. McMurray A, Chaboyer W, Wallis M, Johnson J, Gehrke T. Patients' perspectives of bedside nursing handover. Collegian. 2011;18:19-26.

37. Deshevy-Longhi T, Karpe Dixon J, Olsen D, Grey M. Privacy and confidentiality issues in primary care: Views of advanced practice nurses and their patients. Nurs Ethics. 2004;11:378-393.
38. Burgoon JK. Privacy and communication. Commun Yearb. 1982;6:206-249.

39. Matiti MR, Trorey GM. Patients' expectations of the maintenance of their dignity. J Clin Nurs. 2008;17:2709-2717.

40. Jenkins G, Merz JF, Sankar P. A qualitative study of women's views on medical confidentiality. J Med Ethics. 2005;31:499-504.

41. Rosqvist E. Potilaiden kokemukset benkilökobtaisesta tilastaan ja sen säilymisestä sisätautien vuodeosastolla. Väitöskirja, PhD Thesis, Hoitotieteen ja terveyshallinnon laitos, Oulun yliopistollinen sairaala. Oulu: Oulun yliopisto, University of Oulu; 2003.

42. Stone MA, Redsell SA, Ling JT, Alastair DH. Sharing patient data: Competing demands of privacy, trust and research in primary care. Br J Gen Pract. 2005;55:783-789.

43. Timonen L, Sihvonen M. Patient participation in bedside reporting on surgical wards. J Clin Nurs. 2000;9: 542-548.

44. Whiddett R, Hunter I, Engelbrecht J, Handy J. Patients' attitudes towards sharing their health information. Int $J$ Med Inform. 2006;74:530-541.

45. Moore M, Chaudhary R. Patients' attitudes towards privacy in a Nepalese Public Hospital: A cross-sectional survey. BMC Res Notes. 2013;6:1-5.

46. Braunack-Mayer A, Mulligan EC. Sharing patient information between professionals: Confidentiality and ethics. Med J Aust. 2003;178:277-279.

47. Lämsä R. Potilaskertomus. Etnografia potiluudesta sairaalaosaston käytännöissä. Terveyden ja Hyvinvoinnin laitos. Tutkimus 99. Tampere: Juvenes Print - Suomen Yliopistopaino Oy; 2013.

48. Graneheim UH, Lundman B. Qualitative content analysis in nursing research: Concepts, procedures and measures to achieve trustworthiness. Nurse Educ Today. 2004;24: 105-112. 